\title{
VIOLÊNCIA DE GÊNERO: \\ A Ausência de um Olhar Decolonial na Busca de Respostas Jurídicas
}

\section{Amanda Martinho Resende ${ }^{1}$}

\section{Resumo}

Este artigo pretende investigar, com base em dados estatísticos e a partir de uma perspectiva pós-estruturalista e decolonial, a violência de gênero, bem como o grau de eficácia das medidas legais oferecidas pelo Estado brasileiro para coibi-la. Ele defende que as subjetividades são formadas através de múltiplos discursos, tecnologias e práticasque afetam as imagens que os sujeitos têm de si e dos outros. Assim, argumenta-se que violências poderão ser acionadas caso sejam frustradas as expectativas a respeito das posições que os sujeitos desejam ocupar ou esperam que outros ocupem. Em última instância, coloca-se em xeque a possibilidade de o Estado dirimir a opressão de gênero se não atentar para a heterogeneidade da categoria mulher e a multiplicidade e imbricação das estruturas de poder, inseparáveis inclusive no âmbito dos discursos disseminados pela matriz colonial de poder, que hierarquiza representações de feminilidade, com consequências fundamentais para a experiência de violência da mulher negra.

Palavras chave: Violência, Gênero, Raça, Decolonialidade.

\begin{abstract}
This article intends to investigate, supported by statistics and through a post-structuralist and decolonial perspective, gender violence and the doubtful adequacy of the legal measures offered by the Brazilian State to curb it. It defends that subjectivities are formed through multiple speeches, technologies and practices that affect self-images, as well as constructed images of others. Therefore, it argues that violence can be triggered by frustrated expectations related to the positions subjects desire to occupy or expect others to do so. Ultimately, the
\end{abstract}

\footnotetext{
${ }^{1}$ Graduada em Direito pela Pontifícia Universidade Católica do Rio de Janeiro - PUC-Rio. Atualmente cursando Economia na Universidade Federal do Rio de Janeiro - UFRJ. Email: amandamresende@gmail.com.
} 
article questions the effectiveness of any State measure that tries to reduce gender oppression but fails to recognize the diversity of women as a category and the multiplicity and imbrication of power structures, which are inseparable even within the scope of speeches disseminated by the colonial matrix of power, that produces a hierarchy between feminine representations, with fundamental consequences to black women's experience of violence.

Keywords: Violence, Gender, Race, Decoloniality.

\section{Introdução}

O presente trabalho pretende fornecer um novo enfoque ao estudo da violência de gênero e das medidas judiciais que visam remediá-la. Para tanto, utiliza as perspectivas pósestruturalista e decolonial para viabilizar uma melhor compreensão das relações raciais e de gênero, bem como dos mecanismos de produção das subjetividades, que estão intimamente ligados às dinâmicas de violência. Nesse sentido, ele parte da premissa de que os sujeitos são formados por numerosos discursos, símbolos, tecnologias e práticas, disseminados e tornados hegemônicos por uma matriz colonial de poder (MIGNOLO, 2009, p. 254) que, desde o início do período moderno, impôs aos povos colonizados da América Latina - e de outras regiões - uma existência definida em termos eurocêntricos, que viabiliza a plena realização do projeto colonial, constantemente reatualizado, das potências capitalistas.

Assim, procura-se investigar a influência desses discursos, marcados pelas diferenças de gênero, raça, classe, etc., sobre as representações que os sujeitos têm de si e dos outros, sobre as posições que tentarão ocupar e sobre as expectativas construídas em razão dessas representações, expectativas que, se por algum motivo, forem frustradas, podem desencadear violências.

Por outro lado, o reconhecimento da complexa imbricação ${ }^{2}$ entre as diversas estruturas de dominação - de gênero, raça, etc. - que formam a matriz colonial de poder e hierarquizam a sociedade coloca em xeque qualquer tentativa, por parte do Estado, de coibir

\footnotetext{
"“Compreender a imbricação das opressões não se trata de colocar categorias que conformam uma somatória de experiências, ou uma interseção de categorias analíticas (CRENSHAW, 1993), se trata de entender como estas têm atravessado historicamente nossa região desde o colonialismo até a colonialidade contemporânea e como elas têm se expressado em certos sujeitos que não têm tido privilégios de raça, classe, sexo e sexualidade, como no caso das mulheres negras, indígenas e camponesas da região" (CURIEL, 2016, p. 80). Tradução livre.
} 
a violência contra a mulher que não atente para outras dimensões do problema que não a ordem de gênero. Isso porque estas supostas soluções, ao não levarem em conta a heterogeneidade da categoria mulher, acabam reproduzindo desigualdades e desencadeando novas formas de violência contra mulheres marginalizadas.

Nesta linha, serão analisadas, com base nas contribuições de Pereira (2016; ALMEIDA \& PEREIRA, 2012) e Flauzina (2015; 2016), duas medidas legais atualmente em vigor no Estado brasileiro, a Lei Maria da Penha e o crime de feminicídio, como exemplos de respostas jurídicas, em parte, frustradas, que buscam combater violências relacionadas à desigualdade de gênero.

\section{A construção discursiva dos sujeitos e a violência de gênero}

Os sujeitos são formados e categorizados de forma hierárquica através de mecanismos discursivos. Com efeito, cada cultura conta com uma multiplicidade de discursos sobre gênero, raça, classe, orientação sexual, etc., lembrando que a imbricação entre essas categorias reflete-se na formulação de cada um desses discursos. Assim, existem incontáveis discursos acerca da feminilidade, que longe de serem coerentes e harmônicos, são contraditórios e conflitantes (MOORE, 2015, p. 28-30), como os discursos que exaltam a maternidade, os que ressaltam a fragilidade e a delicadeza da mulher e os que defendem a força da mulher independente e autônoma. Essas posições coexistem na vida de muitas mulheres. O mesmo ocorre com as diversas branquitudes, negritudes e masculinidades.

Diante disso, esses numerosos discursos - alguns hegemônicos, que sustentam a universalidade de experiências e posições particulares e excludentes, como os propagados pela matriz colonial de poder; outros marginalizados e marcados pela força da resistência, que luta pelo reconhecimento e coexistência das diversas formas de vida - entram em disputa para constituir indivíduos, que assumem múltiplas e contraditórias posições de sujeito marcadas pelo gênero, pela raça, etc. A partir desses discursos, os indivíduos construirão diversas imagens representativas marcadas por aquelas categorias e investirão nas posições que desejam ocupar, tendo em vista as vantagens que elas prometem oferecer (MOORE, 2015, p. 22-27, 36). O pai provedor, por exemplo, será respeitado e admirado não só por sua família, que em resposta, obedecerá às suas ordens, mas também por amigos e colegas de trabalho. 
Neste ponto, convém salientar que tais benefícios são nada menos do que os efeitos materiais e de poder advindos dos discursos e práticas institucionais que produzem as categorias hierarquizadas e, posteriormente, sancionam as subjetividades que se conformam a elas:

\begin{abstract}
É importante reconhecer que o investimento [em determinadas posições de sujeito] é uma questão não apenas de satisfação emocional, mas de benefícios materiais sociais e econômicos muito reais que são a retribuição do homem respeitável, da boa esposa, da mãe poderosa ou da filha bem comportada em muitas situações sociais. É por essa razão que modos de subjetividade e questões de identidade estão ligadas a questões de poder, e aos benefícios materiais que podem ser uma conseqüência do exercício desse poder (MOORE, 2015, p. 37).
\end{abstract}

Vê-se, deste modo, que as fantasias de poder dos sujeitos estão intimamente ligadas às fantasias de identidade (MOORE, 2015, p. 38). Ocupar certas posições significa adquirir certos poderes e prestígio em relação a outros sujeitos e posições, menos valorizados nos discursos dominantes. Este cenário se complexifica ao considerarmos que o poder, a força e a violência são frequentemente sexualizados e racializados (MOORE, 2015, p. 34-35). Isso significa que, em certos contextos, o poder manejado por mulheres será consequência da corporificação de uma posição de sujeito marcada pelo gênero masculino.

Ocorre que, quando os indivíduos não conseguem atingir estas posições de sujeito de forma plena ou satisfatória - o que inclui possíveis conflitos entre posições contraditórias assumidas por um mesmo indivíduo -, ou ainda, quando não recebem o reconhecimento ou os benefícios que esperavam obter ao assumi-las, suas representações de si são abaladas, o que gera conflitos que podem deflagrar violências (MOORE, 2015, p. 39). Por outro lado, as expectativas em relação às posições de sujeito dos outros, quando frustradas, podem ter os mesmos efeitos. A violência é uma forma de garantir a eficácia daquelas posições e funciona, portanto, como um poderoso mecanismo de reprodução dos discursos a respeito do gênero, da raça, da sexualidade, etc., e muitas vezes é invocada tanto para afirmar o êxito da interiorização de certo discurso, transformado em posição de sujeito, quanto para "dirimir" conflitos gerados pela não correspondência entre as auto-representações dos individuos e as posições de sujeito que eles de fato ocupam.

Feitas essas considerações, podemos descrever a violência de gênero como aquela provocada por conflitos que surgem em razão da frustração de expectativas vinculadas aos papeis que supostamente devem ser assumidos por sujeitos femininos e masculinos. A 
violência de gênero, portanto, não se resume à violência de homens contra mulheres, já que pode ser perpetrada pela mãe ou pai contra seus(uas) filhos(as) e está presente, inclusive, em relacionamentos homossexuais. Ademais, sua dinâmica é complexa e não pode ser compreendida por meio de um olhar dirigido exclusivamente às atitudes e motivos do agressor - o que não retira sua total responsabilidade pela violência -, pois é necessário que haja uma visão abrangente da relação conflituosa, o que inclui as posições de sujeito e as expectativas da vítima.

Ainda que a violência de gênero não se restrinja à violência contra a mulher, é necessário reconhecer que a interseção entre elas é consideravelmente grande. Isso porque as representações discursivas da violência são sexualizadas (MOORE, 2015, p.43-44) e, por isso, muitos homens buscam afirmar suas masculinidades por meio da agressividade, atributo tipicamente representado como masculino. De acordo com esta lógica, a violência confirma a identidade masculina, que é retribuída com o poder masculino que, por sua vez, legitima o uso da violência.

De forma previsível, o ambiente mais propício para a proliferação da violência contra a mulher, é o espaço doméstico e familiar. De fato, a família mononuclear da sociedade ocidental é uma poderosa instituição em torno da qual circulam numerosos discursos que reforçam papeis marcados pelo gênero. No âmbito da família tradicional do ocidente - ou mesmo em relações íntimas de afeto não matrimoniais -, o marido/pai/companheiro/namorado/ficante possui o poder disciplinador (PEREIRA, 2016, p. 66), isto é, o poder de corrigir as atitudes “inapropriadas" de sua esposa/filha(o)/companheira/namorada/ficante, podendo, inclusive, usar a violência como forma legítima de garantir a eficácia de sua correção. Assim, caso este homem se veja ameaçado em suas posições de sujeito - provedor, chefe de família, homem ativo da relação -, ou caso a esposa ou os(as) filhos(as) não supram suas expectativas quanto às posições de sujeito que devem assumir, a violência se coloca como um possível instrumento retificador.

As observações que fizemos até agora dão conta apenas da dimensão de gênero relacionada à violência doméstica e familiar contra a mulher. É necessário, portanto, aprofundar nossa análise e levar em conta outros fatores determinantes. 


\section{Contextualizando a violência doméstica e familiar contra as mulheres negras}

As estruturas de poder articulam-se para determinar as heterogêneas formas de vida em nossa sociedade hierarquizada, impactando, de modo desigual, a vida de mulheres diferentemente localizadas. Evidentemente, isto se aplica também aos contextos de violência e, no que se refere às mulheres negras, o entrecruzamento entre gênero e raça as coloca em uma posição cujo status social inferior modifica a experiência da violência doméstica e familiar. Além disso, por serem indissociáveis, as dimensões de gênero e de raça - e os discursos que as constituem - irão atuar de forma conjunta nas dinâmicas de violência do ambiente doméstico, influenciando tanto os momentos nos quais a violência será evocada quanto os modos através dos quais ela será exprimida.

Entretanto, a análise da estrutura de dominação racial e de suas implicações para o contexto da violência doméstica e familiar contra a mulher é praticamente inexistente no Brasil, não obstante os inúmeros estudos desta forma de violência. Neste ponto, os conceitos de subinclusão e superinclusão cunhados por Kimberlé Crenshaw (2002, p. 174-177) são úteis para compreendermos a invisibilidade das experiências de violência vividas por mulheres negras. Com efeito, quando a imbricada relação entre gênero e raça gera dinâmicas de violência que são interpretadas como consequência exclusiva do gênero feminino da vítima - por exemplo, quando uma mulher negra é controlada rigidamente em sua sexualidade, em razão do imaginário racista e sexista que a hipersexualiza -, temos uma superinclusão, isto é, uma absorção indevida pela ordem do gênero, que oculta outras estruturas determinantes naquele contexto interseccional. Por outro lado, quando as agressões sofridas por mulheres negras não espelham a realidade das mulheres brancas - insultos racistas, com o intuito de humilhar e diminuir a autoestima da vítima -, elas não são nomeadas como violência doméstica ou nem mesmo identificadas ${ }^{3}$, o que evidencia o fenômeno da subinclusão, ou seja, não são reconhecidas como um problema causado nem pela desigualdade de gênero nem pela desigualdade racial, apesar de ser fruto de ambas.

\footnotetext{
${ }^{3}$ As entrevistas de Bruna Pereira com mulheres negras vítimas de violência doméstica apontaram para uma dificuldade real das entrevistadas em admitir que eram vítimas de racismo ou de insultos racistas por pessoas próximas. Além disso, este assunto nunca surgia de forma espontânea durante os relatos de violência doméstica, e era preciso que a entrevistadora fizesse perguntas diretas e reiteradas sobre o tema para que obtivesse respostas que, ainda assim, se mostravam tímidas. Por fim, mesmo quando as ofensas e discriminações raciais eram reconhecidas, estas não eram vistas como parte integrante do contexto mais amplo de violência doméstica (PEREIRA, 2016, p. 173, 177-179).
} 
Como abordar a violência de gênero de modo que todos os elementos importantes sejam considerados? Uma possível resposta está no projeto decolonial (MIGNOLO, 2009; LUGONES, 2015), cuja perspectiva põe em relevo a necessidade do sistema mundial de poder capitalista, iniciado com o período moderno/colonial, mas constantemente reatualizado, de manter as subordinações por gênero e por raça para garantir o funcionamento da matriz de poder colonial. Nesta linha, as colonialidades do poder, do saber e do ser processos históricos de subjetificação e de subordinação política, econômica, cultural e epistemológica, originados da intolerância da modernidade para com a existência de múltiplas cosmovisões (LUGONES, 2015, p. 943) - continuam operando e têm no âmbito privado da vida doméstica um forte aliado na manutenção das hierarquias sociais. A violência, instrumento de autoafirmação e de subjugação profundamente conectado ao racismo e ao sexismo, é uma herança histórica do colonialismo, naturalizada cotidianamente no contexto familiar (ALMEIDA; PEREIRA, 2012, p. 60). A esse respeito, frise-se novamente que o sentido aqui atribuído ao termo família tem sua origem no ocidente (OYÈWÚMI, 2000), e é um dos pilares da matriz colonial de poder.

Observe-se que o acesso pleno e privilegiado de homens brancos ao mercado de trabalho e, portanto, ao mundo público e à cidadania, só são possíveis em razão das opressões por gênero e por raça. Assim, a colonialidade do poder exige que mulheres negras e brancas assumam as tarefas domésticas e os cuidados com os filhos, mas as primeiras devem, além disso, sustentar suas famílias - uma realidade em suas vidas desde o fim da escravização -, o que reforça seu aprisionamento, pois são obrigadas a aceitar ocupações mal remuneradas e pouco valorizadas. Esta situação é agravada pela luta das mulheres brancas por reconhecimento e espaço no mercado de trabalho, uma vez que são as mulheres negras que, enquanto empregadas domésticas, irão substituí-las em suas tarefas, sem, contudo, usufruírem dos benefícios econômicos de seu trabalho. Portanto, podemos dizer que o confinamento das mulheres negras na esfera privada se perpetua mesmo no trabalho fora de casa, impondo-lhes o risco de serem violentadas no âmbito doméstico do empregador (ALMEIDA; PEREIRA, 2012, p. 57-58).

Assim como as mulheres brancas, os homens negros viram na exploração e inferiorização da mulher negra uma oportunidade para elevarem seu status social. Já durante o período colonial, o patriarcado e a opressão de gênero eram as bases de certa solidariedade 
entre homens brancos e negros. Entretanto, a condição racial dos homens negros vem impedindo que desfrutem de todos os privilégios assegurados à masculinidade. Em razão disso, muitos transformaram a luta contra o racismo na luta para assumir sua "posição de direito" na sociedade patriarcal, em igualdade com homens brancos, como demonstraram as feministas negras norte-americanas (HOOKS, 1982). Para tanto, deveriam subjugar e impor limites às suas parceiras, cuja "autonomia excessiva”, supunham eles, era responsável por sua emasculação.

$\mathrm{Na}$ verdade, por terem sua humanidade negada durante a escravidão, os "machos" e "fêmeas" escravizados não puderam compartilhar dos atributos e representações típicas da masculinidade e feminilidade hegemônicas, isto é, brancas (LUGONES, 2015, p. 937). Tal fato, que ainda persiste, acarreta graves consequências para as relações interpessoais cotidianas no contexto domiciliar. Em suas entrevistas com mulheres negras vítimas de violência doméstica, Bruna Pereira (2016, p. 162-164) identificou situações em que o marido, também negro e muitas vezes mais escuro do que a esposa, busca mitigar sua suposta inferioridade racial por meio da afirmação de sua masculinidade, seja através da ênfase de seu papel como provedor - o que envolve comentários constantes e humilhantes a respeito da dependência econômica da companheira -, seja mediante o acesso sexual a mulheres brancas, objeto sexual compartilhado com os homens brancos, o que simultaneamente aproxima as duas masculinidades e seus privilégios e diminui a posição da esposa negra (p. 127-131).

É importante destacar que a feminilidade branca hegemônica coloca-se como o referencial de feminilidade para as mulheres em geral, o que gera frustrações tanto em mulheres não brancas, por não serem capazes de atingir aquele padrão normativo - que lhe é negado de forma automática -, quanto em seus parceiros - brancos ou negros -, cujas expectativas em relação às condutas e aos papeis daquelas mulheres não são atendidas, intensificando-se, assim, possíveis conflitos desencadeadores de violência.

Ademais, faz-se necessária a desmistificação dos discursos a respeito da miscigenação. Muitos acreditam que ela é uma prova de que o racismo não existe ou é atenuado pelo maior número de relacionamentos e casamentos inter-raciais. É preciso recordar, todavia, que a miscigenação funcionou como projeto de genocídio do povo negro, posto que buscava nada menos do que o embranquecimento progressivo da população 
brasileira. Por isso, a ausência de segregação racial explícita no Brasil de forma alguma torna o racismo mais brando em comparação com o de outros países. Os maiores índices de casamento inter-racial significam simplesmente que as relações raciais operam a partir de uma lógica diferente: longe de evidenciarem uma suposta harmonia racial, esses relacionamentos retratam espaços de proliferação de hierarquias raciais e de comportamentos racistas (PEREIRA, 2016, p. 38). Um exemplo é o desapontamento dos pais quando os(as) filhos(as) são mais escuros do que o esperado. Neste caso, a percepção de que houve uma aproximação indesejada - por meio do laço consanguíneo - com a raça considerada inferior estimula estes homens a assumirem posições defensivas em relação à sua identidade racial, o que envolve, muitas vezes, o uso da violência para marcar um distanciamento em relação aos(às) filhos(as) e à esposa/mãe, considerada culpada pela presença da "mancha afrodescendente" na família (PEREIRA, 2016, p. 122-124).

Considerando tal horizonte das relações raciais no Brasil, vejamos agora as representações discursivas e as imagens da feminilidade negra e os sentidos que estas adquirem no contexto familiar e nas dinâmicas de violência doméstica. Para tanto, devemos retornar ao período da escravização, uma vez que este foi determinante na construção daquelas imagens. Com efeito, as mulheres negras escravizadas eram obrigadas a trabalhar exaustivamente, nas mesmas condições impostas aos homens negros. Estavam sujeitas a constantes espancamentos e a estupros sistemáticos, já que eram vistas como meros objetos a serviço dos interesses econômicos e sexuais de seus proprietários. Ademais, sua inferiorização e desumanização as destituíam dos traços mais valorizados da feminilidade branca: a beleza e a virtude - pureza e castidade - femininas. Por tudo isso, integram o imaginário da população brasileira as seguintes representações da mulher negra: trabalhadora incansável, dotada de extraordinária força física, sexualmente disponível, puta, sedutora, feia (ALMEIDA; PEREIRA, 2012, p. 56).

Todas essas imagens representativas da feminilidade negra apareceram nas entrevistas de Bruna Pereira com mulheres pretas e pardas vítimas de violência doméstica, determinando os espaços e as posições de sujeito que elas poderiam ocupar e conferindo significados às suas vivências. Podemos perceber, ainda, que as expectativas e as atitudes dos parceiros em relação a elas foram influenciadas por essas imagens. Por serem vistas como 
trabalhadoras, as mulheres negras ${ }^{4}$ - sobretudo as pretas - são muitas vezes exploradas economicamente por seus companheiros, que exigem não só que elas trabalhem, mas que sejam provedoras exclusivas do lar. Neste cenário, qualquer contestação da parte dela pode acionar práticas violentas - de ofensas racistas a agressões físicas (PEREIRA, 2016, p. 150158). Além disso, a ideia de que as mulheres negras são fortes e resistentes pode motivar condutas absurdamente violentas, afinal, "elas aguentam” (ALMEIDA; PEREIRA, 2012, p. 59).

No que tange à hipersexualização da mulher negra - tanto pretas quanto pardas, mas com maior ênfase às segundas, por sua aproximação com a figura mítica da mulata (GONZALEZ, 1984, p. 230) -, podemos citar como principal consequência o controle severo de sua sexualidade e de suas relações pessoais. Com relação às mulheres pretas, este controle pode ser considerado dispensável pelos parceiros, já que, por não se encaixarem no padrão de beleza feminino, tipicamente branco, muitas são consideradas pouco atraentes. Esta atitude despreocupada se transforma quando eles percebem que há alguma chance de envolvimento com outro homem. Nesta hipótese, o grupo de mulheres negras como um todo é atacado e condenado, e as parceiras são acusadas de agirem ativa e maliciosamente na sedução de seus pretendentes (PEREIRA, 2016, p. 136-149, 175). Por fim, frise-se que o status social inferior que lhes é atribuído - por serem mulheres e negras -, bem como a constante desvalorização de sua humanidade, as colocam em posição de vulnerabilidade em relação a violências sexuais, ofensas verbais e humilhações - explicitamente racistas ou não (ALMEIDA; PEREIRA, 2012, p. 58-59).

Essas dinâmicas estão presentes na vida de muitas mulheres negras, independentemente da classe social. Contudo, é inegável que a pobreza limita as possibilidades de enfrentamento da situação de violência (ALMEIDA; PEREIRA, 2012, p. 56). Quando há dependência econômica da vítima em relação ao agressor - o que é mais provável se ela for pobre e não puder contar com a ajuda de parentes, normalmente, também pobres -, abandonar o ofensor pode ser inviável. Ademais, a pobreza dificulta o acesso a meios de proteção a direitos. As vias institucionais para a efetivação de direitos muitas vezes não são acessíveis para as camadas mais pobres da população e, mesmo quando isso não é verdade e o acesso é garantido, a estrutura e os mecanismos de apoio disponíveis são

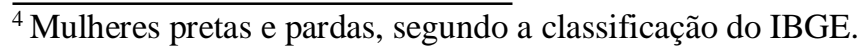


insuficientes e inadequados para o atendimento das necessidades específicas dessas mulheres, que precisam de uma gama articulada de serviços e infraestruturas: abrigos e programas de habitação, programas de qualificação e de inserção no mercado de trabalho, creches, serviços de saúde, etc (CRENSHAW, 2010, p. 1245-1246). Vale dizer que, se os direitos básicos garantidos pela Constituição Federal não lhes fossem negados em um primeiro momento, não haveria necessidade de mobilizar tantos recursos e serviços no âmbito da prevenção e da coibição da violência contra elas.

Nesse sentido, é imperioso ressaltar: a maioria das mulheres negras está nas classes sujeitas à vulnerabilidade social, uma vez que gênero e raça interferem diretamente nas oportunidades de acesso ao mercado de trabalho, que discrimina mulheres, homens negros e, de forma ainda mais aguda, mulheres negras, que possuem os piores rendimentos e as maiores taxas de desemprego. Em 2015, a taxa de desocupação das mulheres negras era de $13,6 \%$, em contraste com os porcentuais de $9,8 \%$ para mulheres brancas, $8,7 \%$ para homens negros e $7 \%$ para homens brancos. No mesmo ano, 49,7\% das mulheres negras ocupadas recebiam, como renda mensal, até um salário mínimo, enquanto 29\% das mulheres brancas, $34,1 \%$ dos homens negros e $17,9 \%$ dos homens brancos encontravam-se na mesma faixa de rendimento (IPEA, 2015a).

Deste modo, são extremamente relevantes os efeitos da imbricação entre gênero, raça e classe sobre a experiência da violência. Sem prejuízo de outras formas de constituição e intensificação mútua, podemos concluir que o entrelaçamento entre as opressões por gênero e raça coloca a mulher negra como a mais provável vítima tanto da violência doméstica quanto da pobreza. Por sua vez, a opressão por classe dificulta sobremaneira a saída desta mulher da situação de violência, sobretudo por razões financeiras e educacionais - esta última interfere não só nas oportunidades no competitivo mercado de trabalho, que lhe reserva empregos degradantes, mas no acesso, nitidamente prejudicado, a informações sobre direitos e garantias enquanto cidadã. Por fim, esta situação de vulnerabilidade é reforçada pelo racismo e pelo machismo institucionais:

(...) os maus atendimentos e as revitimizações têm sido relatados com frequência pelas mulheres em geral, quando buscam os órgãos públicos para protegê-las e combater a violência em que se encontram. A pressão de agentes públicos para privatizar o crime de violência contra elas, tornandoo menos relevante aos olhos da sociedade e do poder público tem sido uma constante, o que se evidencia, muitas vezes, sob a forma de violência 
institucional. Embora não se tenha dados apreendidos sobre a cor das mulheres que mais estão a ela submetidas, não é difícil supor que as pretas e pardas são acolhidas com menos atenção e menor credibilidade (ALMEIDA; PEREIRA, 2012, p. 56-57).

Considerando todo o exposto acima, nos tópicos seguintes, analisaremos os limites da Lei Maria da Penha e do crime de feminicídio no que toca à prevenção da violência contra mulheres negras.

\section{A Lei Maria da Penha e suas limitações}

Em 2006, foi promulgada a Lei 11.340, apelidada Lei Maria da Penha em homenagem a Maria da Penha Maia Fernandes, vítima de duas tentativas de homicídio pelo ex-marido em 1983, uma delas responsável por deixá-la paraplégica. Em 2002, depois de anos de omissão e somente após o caso ser levado à Comissão Interamericana de Direitos Humanos, que condenou o Estado Brasileiro por sua inércia e tolerância em relação à agressão, o processo judicial foi encerrado, com a consequente prisão do ex-marido.

Fruto dos esforços da militância feminista e do engajamento político de variados setores da sociedade, a Lei Maria da Penha vem sendo aclamada - inclusive no âmbito internacional - por seu conteúdo inovador. Por certo, a lei é uma grande conquista, na medida em que (i) aborda a violência doméstica contra a mulher com a devida seriedade, buscando desnaturalizá-la, além de desmistificar a dicotomia entre as esferas pública e privada, na qual esta última seria entendida como o espaço do apolítico e da autonomia privada, não comportando, assim, qualquer intervenção estatal; (ii) oferece um poderoso aporte teórico, conceitual e jurídico sobre o tema, com forte conteúdo educativo; e (iii) mobiliza diversos órgãos públicos e setores da sociedade civil para o devido enfrentamento desta forma de violência, reconhecendo a importância de um enfoque multidisciplinar e intersetorial no tratamento do problema.

Contudo, a referida lei nem sempre atenta para as múltiplas experiências de vida de mulheres diferentemente localizadas e, por isso, não oferece mecanismos suficientes capazes de lidar de forma adequada com as especificidades de realidades silenciadas. Um bom exemplo disso é a invisibilidade das dinâmicas racistas que atravessam o horizonte da violência doméstica contra a mulher, o que torna a própria violência indetectável em alguns contextos (PEREIRA, 2016, p. 173, 177-179), além de prejudicar a eficácia das estratégias 
de enfrentamento, como no caso de grupos de reflexão e programas de recuperação e reeducação que não se preocupam em orientar os agressores quanto às questões raciais envolvidas.

Ademais, o viés punitivista da lei - acentuado na prática pela dificuldade de implementação de todas as suas diretrizes e normas, sobretudo aquelas voltadas para a prevenção da violência e para a proteção da vítima - só se sustenta enquanto tiver a “branquitude como parâmetro" (FLAUZINA, 2015, p. 138). Por certo, busca-se solucionar o sexismo do sistema de justiça criminal e toda a inefetividade que ele acarreta por meio do racismo, profundamente arraigado neste sistema, e da desvalorização dos corpos negros, tidos como descartáveis, o que, por consequência, vulnerabiliza ainda mais as mulheres negras, duplamente vitimadas: são alvo do encarceramento em massa da população negra e a base na qual o sistema de justiça criminal se ampara, já que é a "sua exploração sexual, emocional e financeira" (FLAUZINA, 2015, p. 139) que torna possível o encarceramento masculino. Voltaremos neste assunto mais adiante.

No que tange à Lei Maria da Penha, convém sublinhar que sua rigidez com relação à punição do agressor é realçada quando a violência atinge mulheres negras, já que, neste caso, o punitivismo se coloca como única estratégia de coibição possível. Isso porque os conflitos na zona do não ser ${ }^{6}$ são primordialmente resolvidos por meio da violência e da expropriação, ante o restrito acesso aos mecanismos legais e institucionais disponíveis na zona do ser. Portanto, há uma enorme dificuldade em implementar, no âmbito daquela zona, as medidas preventivas e protetivas dirigidas à vítima e ao agressor, e que poderiam, se devidamente aplicadas, enfrentar a violência doméstica de forma eficiente. Respostas jurídicas promissoras estão muito distantes, por exemplo, da realidade das favelas, espaços marcados pela ausência do Estado - ou por sua presença violadora - e pela consequente deficiência na fiscalização do cumprimento daquelas medidas. Na zona do não ser, portanto, a faceta

\footnotetext{
${ }^{5}$ A branquitude é a identidade racial branca - em regra, não nomeada -, o ponto de vista através do qual os brancos olham para si mesmos e para o mundo, "um lugar de privilégios simbólicos, subjetivos e materiais palpáveis que colaboram para reprodução do preconceito racial, discriminação racial "injusta" e do racismo" (CARDOSO, 2011, p. 81).

${ }^{6}$ Segundo Grosfoguel (2011, p. 11), o racismo separa aqueles que estão acima da linha do humano - zona do ser -, isto é, aqueles que são reconhecidos em sua humanidade, daqueles que estão abaixo desta linha - zona do não ser, no vocabulário de Fanon - considerados não/sub-humanos. A zona do ser garante o gozo de direitos, o acesso a recursos materiais e o reconhecimento social de suas subjetividades, epistemologias e espiritualidades, todos os quais negados na zona do não ser.
} 
punitivista da Lei Maria da Penha é a única "garantia" oferecida à vítima, o que, frequentemente, vai de encontro aos seus interesses.

Vejamos um exemplo no qual a inflexibilidade com relação à punição do agressor acaba prejudicando a escuta da vítima. Quando a aludida Lei foi promulgada, havia uma enorme preocupação em se evitar a impunidade chancelada, anteriormente, pelo modelo conciliatório da Lei 9.099/95 (FLAUZINA, 2015, p. 124-125). Isso porque muitos dos delitos que se enquadram na violência doméstica, à época, só podiam ser processados mediante ação penal pública condicionada à representação da vítima. Muitas mulheres eram coagidas por seus agressores, com quem mantinham relações íntimas de afeto, a renunciar à representação, o que impossibilitava a continuidade da ação penal. Esta situação era agravada pelo instituto da renúncia tácita: durante o procedimento de conciliação, a vítima devia, a cada reunião, exercer seu direito de ratificação da representação. O não comparecimento a uma reunião implicava, automaticamente, no arquivamento do processo.

Para garantir a autonomia da manifestação da vontade da mulher, a Lei Maria da Penha (art. 16), e o Supremo Tribunal Federal (ADI $\mathrm{n}^{\circ} 4.424 / \mathrm{DF}$ ), optaram por, paradoxalmente, dificultar a ingerência da vítima sobre o processo penal. Com efeito, a lei determina que a renúncia à representação só é possível na presença do juiz, em audiência marcada especificamente para este fim e realizada antes do recebimento da denúncia, e desde que ouvido o Ministério Público. Cabe registrar que a estrutura em muitos sentidos ainda precária da Defensoria Pública vem impedindo que mulheres negras e pobres, principais usuárias da assistência judiciária gratuita, recebam a devida orientação quanto aos seus direitos e, portanto, possam se retratar, exercendo seu direito de renúncia à representação. Por sua vez, o STF decidiu que todo crime de lesão corporal associado à violência doméstica contra a mulher, independentemente de sua gravidade, seria processado por meio de ação penal pública incondicionada, o que significa que, a partir daquele momento, a representação da vítima seria dispensável nos casos de lesão corporal leve vinculados ao âmbito doméstico (FLAUZINA, 2015, p. 125-130). Esse movimento em direção à garantia da persecução penal afasta o envolvimento das mulheres com os processos.

A postura punitivista adotada pela lei é um reflexo do pensamento da militância feminista (branca), que acredita que a eficiência do sistema de justiça criminal se confunde com punição, de preferência, por meio do encarceramento. Este posicionamento é 
compreensível, já que pode ser interpretado como uma inflexível resposta à terrível indiferença, tolerância e naturalidade com que a violência doméstica contra a mulher vem sendo tratada. Porém, esta lógica contrasta fortemente com os interesses das mulheres que resistem no cotidiano a esta forma de violência (FLAUZINA, 2015, p. 130-131).

Em pesquisa realizada pelo IPEA (2015b, p. 77), foi constatado que $80 \%$ das mulheres vítimas de violência doméstica que procuravam a ajuda da justiça não consideravam a prisão de seu agressor - com quem mantinham relações domésticas, familiares ou íntimas de afeto - como uma solução satisfatória para seu problema. Este dado pode ser interpretado à luz do fato de que, na época em que a violência doméstica ainda era competência dos Juizados Especiais Criminais (JECrim), as mulheres pobres temiam eventuais imposições de penas privativas de liberdade contra seus parceiros e inclusive renunciavam à representação, pois a prisão de seus companheiros significava a perda de uma renda essencial para suas famílias (AMORIM, 2007, p. 7-8).

Vê-se, então, que o punitivismo da Lei Maria da Penha, para além de seu papel simbólico na formação de um pensamento que não admite a banalização da violência contra a mulher, oculta, em seu interior, um olhar insensível às necessidades de mulheres negras e/ou pobres, que desejam, primordialmente, a suspensão das agressões e a responsabilização do autor na medida do possível ${ }^{7}$, tendo em vista os laços familiares e de afeto entre vítima e agressor (FLAUZINA, 2015, p. 131).

Este punitivismo é agravado pela prática judiciária cotidiana, que nem sempre observa as possibilidades oferecidas pela Lei 11.340/06 e, em algumas situações, descumpre frontalmente suas diretrizes e normas. É o caso dos frequentes desmembramentos das prestações jurisdicionais cíveis e criminais (IPEA, 2015b, p. 90-91, 102-103), o que se tornou a regra no âmbito dos Juizados de Violência Doméstica e Familiar contra a Mulher (JVDFM), que declinam, em favor das Varas de Família, sua competência cível, restringindo-a a

\footnotetext{
${ }^{7}$ Uma resposta interessante para essas demandas, plausível nos casos menos graves, é a suspensão condicional do processo (FLAUZINA, 2015, 132-135) atrelada à exigência de que o réu se submeta, por no mínimo dois anos, a acompanhamento psicológico e/ou participação em grupos de reflexão. Este procedimento vem sendo adotado com muito sucesso em alguns locais, como no Distrito Federal (ASPER Y VALDÉS et al., 2011, p. 101-120). Dentre suas vantagens, destacam-se: maior colaboração por parte da vítima, que vê seus interesses sendo atendidos; responsabilização mais rápida e mais efetiva do agressor, evitando-se, com isso, o risco da prescrição; prevenção de novas violências, em decorrência do monitoramento proporcionado pelo aparato multidisciplinar; maior acesso à Justiça, já que a vítima pode contatá-la "de forma ágil e desburocratizada" (FLAUZINA, 2015, p. 134) a qualquer momento durante a suspensão do processo.
} 
medidas de urgência, muito embora a Lei Maria da Penha tenha expressamente afirmado a competência híbrida daqueles (art. 14), e a despeito das incontáveis vantagens ligadas a um tratamento conjunto e integrado de todas as questões jurídicas relacionadas à coibição da violência doméstica, a saber: a economia do tempo e do dinheiro da assistida, que não terá que se deslocar entre diferentes varas e defensorias públicas; a melhoria no acesso ao Judiciário, proporcionada pela simplificação de sua estrutura institucional, tornada mais compreensível para leigos; o conhecimento profundo e detalhado, pelo defensor e pelo juiz do JVDFM, da situação particular vivida pela assistida, o que garante uma assistência jurídica e decisões judiciais mais adequadas e bem informadas.

Se a competência híbrida dos JVDFM fosse posta em prática, esses não estariam limitados às soluções penais que, afinal, são as medidas menos visadas pelas assistidas (IPEA, 2015b, p. 77), e em especial, pelas assistidas negras e pobres (AMORIM, 2007, p. 78). O tratamento independente das questões cíveis - guarda dos filhos menores, dissolução do casamento ou da união estável, partilha de bens, prestação de alimentos, etc. - em varas de família comuns que desconhecem o contexto de violência continuada coloca a assistida em situação de desamparo, por afastá-la do Judiciário, repleto de confusos trâmites burocráticos, e por fazer seu esforço inicial ser recomeçado do zero nas varas cíveis, espaço institucional que não está preparado para lidar com suas necessidades especiais. Neste contexto, são novamente as mulheres negras e pobres que mais sofrem com esta deficiência na prestação jurisdicional: como vimos, são elas as que mais buscam soluções não penais, bem como as que mais dependem da assessoria jurídica oferecida pela Defensoria Pública, fragmentada em diversos órgãos, o que significa que a chance de serem assistidas por um único defensor - familiarizado com seu caso particular - em processos que tramitam em varas distintas é extremamente reduzida (IPEA, 2015b, p. 102).

\section{O crime de feminicídio: inócuo na proteção de mulheres, mas poderoso para acentuar as desigualdades entre elas}

Se, por um lado, a Lei Maria da Penha representa um enorme avanço na luta pela erradicação da violência contra a mulher, merecendo, assim, mais elogios do que críticas, por outro, não há nenhum motivo para comemorar a promulgação da Lei 13.104/2015, que instituiu o feminicídio como homicídio qualificado - art. $121, \S 2^{\circ}$, VI, CP - e o incluiu no rol de crimes hediondos - art. $1^{\circ}$, I, da Lei 8.072/90. 
A primeira dificuldade que se coloca diz respeito a qual sujeito a lei pretende proteger. Segundo o inciso VI do art. $121, \S 2^{\circ}, \mathrm{CP}$, aplica-se a qualificadora quando o homicídio for cometido "contra a mulher por razões da condição de sexo feminino". Vê-se, portanto, que uma interpretação literal do referido inciso pode conduzir à exclusão de mulheres trans e travestis do âmbito de sua proteção, em total afronta aos direitos dessas mulheres, já excessivamente vulnerabilizadas pelo violento sistema cisgênero, heteronormativo e misógino que impera em nossa sociedade. A propósito, vale ressaltar que a expectativa de vida de pessoas trans no Brasil é de cerca de 35 anos. Além disso, é significativo o fato de que "o Brasil foi responsável por $40 \%$ dos 2.600 assassinatos [de pessoas trans e travestis] em todo o mundo nos últimos dez anos" (Thomaz, 2018). Esses dados alarmantes não podem ser ignorados e exigem uma resposta imediata e efetiva do poder público.

De um ponto de vista simbólico, a supressão de mulheres trans e travestis promovida pela Lei 13.104/2015 é inaceitável, pois reproduz e potencializa a incessante marginalização desses corpos, rejeitados de tal forma pela sociedade que nem mesmo seu direito à vida é assegurado. Contudo, essa exclusão se torna menos expressiva se considerarmos a completa inocuidade da lei, incapaz de produzir qualquer alteração significativa no quadro de homicídios contra mulheres.

Para adentrar no tema da ineficácia do punitivismo do crime de feminicídio, é pertinente fazer um esboço do quadro geral de homicídios de mulheres no Brasil, através da reunião de algumas estatísticas relevantes. De acordo com o "Mapa da Violência 2015: homicídio de mulheres no Brasil” (WAISELFISZ, 2015, p. 31), entre 2003 e 2013, "as taxas de homicídio de mulheres brancas caíram 11,9\% (...). Em contrapartida, as taxas das mulheres negras cresceram 19,5\%". Isso significa que "a diferença percentual entre as taxas de homicídio de mulheres de ambos os grupos" aumentou expressivamente, passando de 22,9\% para 66,7\% (p. 32). Esses dados revelam não só que as mulheres negras são as maiores vítimas de violências fatais, mas que há um contínuo crescimento na desproporção entre as taxas de homicídio de mulheres brancas e negras.

Ademais, a pesquisa demonstra (p. 48) que a violência que mais atinge as mulheres é a doméstica, haja vista que, em 2014, 67,2\% das vítimas atendidas no Sistema Único de Saúde foram agredidas por parentes próximos, parceiros e ex-parceiros. Acrescente-se que, em 71,9\% dos casos, as agressões se deram na própria residência. Por fim, no que se refere 
aos homicídios de mulheres registrados pelo Sistema de Informações sobre Mortalidade (SIM), em 2013, 50,3\% foram praticados por alguém da família, e 33,2\% cometidos pelo parceiro ou pelo ex-parceiro, o que significa que, em $83,5 \%$ dos casos, o autor do crime é alguém próximo (p. 70).

Na mesma linha, em pesquisa (GARCIA et al., 2015, p. 251-257) realizada pelo IPEA a partir de dados corrigidos do SIM, foi apurado que, entre 2009 e 2011, as mulheres que mais sofreram por mortes violentas foram as negras - que corresponderam a $60,9 \%$ do total de vitimadas - e de baixa escolaridade $-47,1 \%$ das vítimas maiores de 15 anos possuíam menos de oito anos de estudo, em contraste com os $22,1 \%$ que possuíam oito anos ou mais de estudo. As estatísticas demonstram que, para além da ordem de gênero, as dimensões de raça e de classe são extremamente relevantes para a compreensão do contexto no qual se dá a violência.

Pelo exposto, podemos correlacionar os homicídios que atingem mulheres e a violência doméstica e familiar contra as mesmas. A raiz do problema dos feminicídios está no machismo - no controle abusivo dos corpos e das mentes das mulheres, na sua constante inferiorização e subordinação e no poder disciplinador (PEREIRA, 2016, p. 66), que se concretiza sobretudo por meio da violência, seu instrumento mais eficaz - e não no apenamento do crime que, aliás, nunca foi leve. Quanto mais se acredita no poder de persuasão de penas mais duras, mais frustrantes serão os resultados das estatísticas. Se um tempo maior de pena produz alguma consequência, esta seria o reforço do machismo desses homens, reclusos em um ambiente historicamente masculinizado (FLAUZINA, 2016, p. 9798).

Por fim, o que significa apostar em um maior encarceramento? Convém lembrar que o sistema prisional racista e sexista se apoia - e solta todo seu peso - nas mulheres negras para que o encarceramento massivo de homens negros seja minimamente sustentável. De fato, o Estado não é capaz - ou não tem interesse - de carregar esse fardo sozinho, e exige que aquelas mulheres compartilhem dessa responsabilidade. Pela ótica financeira, são elas que, na sua solidão, assumem o papel de provedoras de suas famílias e dos próprios apenados, sejam eles seus companheiros, filhos ou irmãos. Decerto, as condições degradantes e desumanas das prisões são, por si só, um indicativo das incontáveis carências materiais que 
afetam o dia-a-dia dos presos, supridas, em grande medida, por essas mulheres (FLAUZINA, 2016, p. 99).

Além de seu dinheiro, seus corpos estão à disposição para atender às necessidades físicas e emocionais desses homens. Sem dúvida, a exploração sexual das mulheres negras é um poderoso mecanismo de controle e recompensa com o qual o Estado conta para garantir a ordem nas prisões, e sem o qual os apenados, em meio àquele ambiente brutal e deplorável, não teriam nada a perder com a desobediência, instaurando-se, assim, um caos administrativo (FLAUZINA, 2016, p. 100). Entretanto, sua exploração sexual não se resume a esta função disciplinadora. A revista de seus corpos é marcada pelo abuso e pelo desrespeito, que estão em perfeita consonância com o valor atribuído pelos policiais a essas mulheres, destituídas dos traços "honrados" da feminilidade branca:

\begin{abstract}
A revista vexatória invade as cavidades de mulheres que não são detentoras de seus próprios corpos. Atualizando a ordem escravista, seu corpo e sua sexualidade não são tutelados por qualquer tipo de valor moral associada à ideia de feminilidade. O recato e a pureza, que aprisionam o ideal feminino branco, são abandonados pela violação explícita, a disponibilidade e o livre acesso atrelado aos corpos negros. Nas filas das visitas, vê-se uma horda de mulheres "escuras", jovens, idosas, que devem ser revistadas não só pela possibilidade de carregarem objetos proibidos para dentro dos portões. A suspeição justifica a imposição de uma pena autônoma: o abuso sexual legitimado como forma de marcar sua vulnerabilidade, como uma maneira de simbolicamente submetê-las a um regime de constrangimento talhado para seus corpos. [...] A punição dos homens prevê, assim, uma punição complementar às mulheres, condenadas pelo delito de serem a eles conectados, de fazerem parte da mesma comunidade abjeta situada nos contornos da negritude (FLAUZINA, 2016, p. 100).
\end{abstract}

A esse respeito, o depoimento de Cremilda, mãe de um ex-detento, é elucidativo:

Eu vi muita coisa ruim. Uma senhora bem velhinha, magrinha, foi obrigada a ficar nua também. Tímida, ela tentou cobrir a genitália com as duas mãozinhas. Nossa, teve que ouvir coisas absurdas. A agente disse: 'Você não teve vergonha de usar isso pra fabricar bandido pra encher o saco da gente, agora tem vergonha de mostrar?'. Ela tremia de medo. E eu não podia falar nada, porque, se eu reagisse, sabia que meu filho seria espancado (REVISTA FÓRUM, 2014).

A revista vexatória é uma prática institucionalizada nas prisões brasileiras, apesar de frontalmente ilegal e inconstitucional. Muitas(os) visitantes não sabem que esta prática viola seus direitos, e as(os) que têm acesso a essa informação não se arriscam a questionar, pois podem sofrer represálias, como a proibição de novas visitas ou a 
tortura/espancamento/violação sexual dos seus parentes. O procedimento de revista padrão é humilhante e extremamente abusivo, como relata Priscila:

O Estado faz de tudo pra gente abandonar a nossa família. Fazem a gente abaixar, peladas, três vezes de frente, três de costas, fazer quadradinho de 8, de 16, ficar em frente ao espelho, colocar a mão, abrir, passar o papel. (...)Mas a gente não abandona. Só quem abre as pernas ali sabe como é. Aquilo é um estupro (REVISTA FÓRUM, 2014).

Assim, o punitivismo propagado pelo crime de feminicídio tem o propósito de alimentar um sistema penal genocida que tem no corpo negro seu alvo mais almejado. Isso porque o "incremento da punição" não tem qualquer efeito sobre a incidência social das práticas delituosas - que permanece inalterada -, e se torna apenas um discurso simbólico que "opera no sentido de legitimar um sistema extremamente violador. Violador não só de homens, mas também de mulheres", que assumem a árdua tarefa de garantir um mínimo de dignidade a homens que habitam um espaço marcado pela "experiência de expropriação quase absoluta", em detrimento de sua própria integridade física, sexual e psíquica (FLAUZINA, 2016, p. 101).

\section{Conclusão}

As reflexões que fizemos revelam a importância de um olhar atento às imbricadas relações entre as estruturas de opressão que formam a - e são reproduzidas pela - matriz colonial de poder. No âmbito do Estado de Direito, este olhar é indispensável, já que a elaboração - no Legislativo - e a implementação - no Judiciário e no Executivo - de medidas jurídicas adequadas e eficazes pressupõem um profundo entendimento do problema, que deve ser considerado em toda a sua complexidade. Dessa forma, quando o Estado tenta corrigir desigualdades a partir de um olhar míope, ele produz respostas não apenas inócuas, mas potencializadoras dessas desigualdades, o que foi demonstrado a partir do exame das insuficiências e dos perigos presentes nas Leis 11.340/2006 e 13.104/2015 - sem dúvida, em diferentes proporções.

Vimos que as instituições estatais são frequentemente utilizadas para violar pessoas negras, o que as coloca em posição particularmente vulnerável. Como evidenciou Grosfoguel (2016, p. 13), os conflitos na zona do não ser são resolvidos através da violência e da 
expropriação. Isso gera como reflexo, no Brasil - país que, por um lado, localiza-se na zona do não ser a nível global, por pertencer a uma região subordinada da colonialidade do poder (p. 12), e por outro, em razão desta mesma colonialidade, possui uma sociedade racista e hiper-hierarquizada -, o punitivismo como projeto de Estado, modelo de Justiça Penal e estratégia de genocídio da população negra. Por atacarem frontalmente os direitos de mais da metade da população brasileira, os discursos que exaltam o punitivismo devem ser sistematicamente combatidos.

\section{Referências bibliográficas}

ALMEIDA, T. M. C.; PEREIRA, B. C. J. Violência doméstica e familiar contra mulheres pretas e pardas no Brasil: reflexões pela ótica dos estudos feministas latino-americanos. Crítica e Sociedade: revista de cultura política, v. 2, n. 2, Dossiê: Cultura e Política, p. 4263, dez. 2012.

AMORIM, M. S. Acesso à justiça e administração judicial da violência contra a mulher brasileira: políticas de despenalização e de penalização. Disponível em: <http://www.publicadireito.com.br/conpedi/manaus/arquivos/anais/campos/maria_stella_de _amorim.pdf> Acesso em 10 set. 2018.

ASPER Y VALDÉS, L.; BARRETO, F. C. O.; MORATO, A. C.; PELEGRINI, J. V. Lei Maria da Penha, ciclo da violência e a suspensão condicional do processo: percepções da prática experimentada no Distrito Federal. Revista do MPDFT, v. 1, n. 5, p. 101-120, 2011.

CARDOSO, L. O branco-objeto: o movimento negro situando a branquitude. Instrumento: R. Est. Pesq. Educ. Juiz de Fora, v. 13, n. 1, p. 81-93, jan./jun. 2011.

CRENSHAW, K. Mapping the Margins: Intersectionality, Identity Politics, and Violence against Women of Color. Stanford Law Review, vol. 43, n. 6, p. 1241-1299, jul. 2010.

. Documento para o encontro de especialistas em aspectos da discriminação racial relativos ao gênero. Estudos Feministas, vol. 10, n. 1, p. 171-188, jan. 2002.

CURIEL, O. De las identidades a la imbricación de las opresiones: desde la experiencia. In: FLAUZINA, Ana; PIRES, Thula (Org.). Encrespando - Anais do I Seminário Internacional: Refletindo a Década Internacional dos Afrodescendentes (ONU, 2015-2024). Brasília: Brado Negro, 2016. p. 75-89.

FLAUZINA, A. L. P. O feminicídio e os embates das trincheiras feministas. Discursos Sediciosos, n. 23-24, 2016, p. 95-104. 
. Lei Maria da Penha: entre os anseios da resistência e as posturas da militância. In: FLAUZINA, Ana; FREITAS, Felipe; VIEIRA, Hector; PIRES, Thula. Discursos negros: legislação penal, política criminal e racismo. Brasília: Brado Negro, 2015. p. 115-144.

GARCIA, L. P.; FREITAS, L. R. S.; SILVA, G. D. M.; HÖFELMANN, D. A. Estimativas corrigidas de feminicídios no Brasil, 2009 a 2011. Rev Panam Salud Publica, n. 37, p. 251$257,2015$.

GROSFOGUEL, R. What is Racism?Journal of World-Systems Research, [S.1.], v. 22, n. 1, p. 9-15, mar. 2016.

HOOKS, B. Ain't I a Woman: Black Women and Feminism. London: Pluto Press, 1982. GONZALEZ, Lélia. Racismo e sexismo na cultura brasileira. In: SILVA, L. A. et al. Movimentos sociais urbanos, minorias e outros estudos. Ciências Sociais Hoje, Brasília, Anpocs, n. 2, p. 223-244, 1984.

IPEA - INSTITUTO DE PESQUISA ECONÔMICA APLICADA. Retrato das desigualdades de gênero e raça. Brasília: IPEA, 2015a.

IPEA. Violência contra a mulher e as práticas institucionais. Ministério da Justiça, Secretaria de Assuntos Legislativos. Brasília: IPEA, 2015b [Série pensando o Direito, n. 52]. $116 \mathrm{p}$.

LUGONES, M. Rumo a um feminismo descolonial. Estudos Feministas, Florianópolis, v. 22, n. 3, p. 935-952, jan. 2015.

MIGNOLO, W. La idea de América Latina (la derecha, la izquierda y la opción decolonial). Crítica y Emancipación, v.2, n.1, 2009, p. 251-276.

MOORE, H. Fantasias de poder e fantasias de identidade: gênero, raça e violência. Cadernos Pagu, n. 14, p. 13-44, jun. 2015.

OYĚWÙMÍ, O. Family bonds/Conceptual Binds: African notes on Feminist Epistemologies. Signs, Vol. 25, № 4, Feminisms at a Millennium (Summer, 2000), p. 1093-1098. Tradução para uso didático por Aline Matos da Rocha.

PEREIRA, B. C. J. Tramas e dramas de gênero e de cor: a violência doméstica e familiar contra mulheres negras. Brasília: Brado Negro, 2016. 200 p.

REVISTA FÓRUM. "Só quem abre as pernas ali sabe como é. Aquilo é um estupro”, Revista Fórum, 09 de abr. de 2014. Disponível em: <https://www.revistaforum.com.br/quem-abrepernas-ali-sabe-como-e-aquilo-e-um-estupro/> Acesso em: 01 de abr. de 2019.

THOMAZ, D. Reduzida por homicídios, a expectativa de vida de um transexual no Brasil é de apenas 35 anos. Revista Época, 30 de jan. de 2018. Disponível em: <https://epoca.globo.com/brasil/noticia/2018/01/reduzida-por-homicidios-expectativa-devida-de-um-transexual-no-brasil-e-de-apenas-35-anos.html>. Acesso em: 01 de abr. de 2019. 
WAISELFISZ, J. J.Mapa da Violência 2015: homicídio de mulheres no Brasil. Brasília: Flacso Brasil, 2015. 